\title{
Fabrication and research on cone-shaped SOFCs by phase inversion technology
}

\author{
Handuo Wang*1, a , Cuixia Cai ${ }^{2, b}$, Yuan Gao ${ }_{6, \mathrm{f}}^{3, \mathrm{c}}$, Hailang Yu ${ }^{4, \mathrm{~d}}$, Nisha Wang ${ }^{5, \mathrm{e}}$ \\ and Jiang Liu
}

1,2,3,4,5 Institute of Genetic Engineering of Southern Medical University, Guangzhou 510515, PR China

\author{
${ }^{6}$ School of Chemistry and Chemical Engineering, South China University of Technology, \\ Guangzhou 510641, PR China \\ awanghanduo0690@163.com, b240569844@qq.com, '12137865@qq.com, d44018408@qq.com, \\ e515508351@qq.com, f195419316@qq.com
}

\begin{abstract}
Keywords: SOFCs, Cone-shaped, Phase inversion, Microstructure, Cell performance Abstract:Cone-shaped tubular anode substrates were prepared successfully by phase inversion technique. The effect of several kinds of organic additives on the microstructure development of NiO-YSZ anode support has been investigated. The scanning electron microscopy (SEM) results of $\mathrm{NiO}-\mathrm{YSZ}$ anode supports show that the organic additives can greatly influence microstructure of the anode. Electrochemical testing shows that the single cell provides a maximum power output of $350 \mathrm{~mW} / \mathrm{cm}-2$ at $800^{\circ} \mathrm{C}$ using PEG-1000 as additive. The correlation between the electrochemical performance of single cells and microstructure of the anodes had been analyzed in detail. In addition, a two-cell-stack was assembled by connecting cone-shaped anode-supported single cells in series. The chemical performance of the stack had also been tested.
\end{abstract}

\section{Introduction}

Solid oxide fuel cells (SOFCs) have attracted more and more interest due to their fuel flexibility, low pollution emission and high conversion efficiency in converting the chemical energy of fuel into electrical energy ${ }^{[1-6]}$. Cone-shaped tubular SOFCs, as one of the SOFC designs, are composed of a series of cone-shaped anode-supported cell units ${ }^{[7-9]}$. Each unit as a single cell is connected with the next to form tubular structure, which the gas and electricity could transmission in it. This so-called cone-shaped SOFC possess the advantage of higher power density and more flexible stack structure compare to the long tubular design ${ }^{[10-11]}$.

In general, the cone-shaped anode substrates are fabricated by several techniques, such as slip casting, dip coating and so on. Phase inversion technology, as a formation process for polymeric asymmetric membrane, were successfully used for preparation cone-shaped anode substrates in previous works ${ }^{[12-15]}$. In this so-called phase inversion processes, homogeneous solution of polymer and solvent are mixed together and then immersed into a coagulant (non-solvent) which is miscible with the solvent but immiscible with the polymer. Phase instability of the solution is induced exclusively by counter diffusion between the solvent and non-solvent, leading to phase separation to form membrane with a so-called sandwich structure ${ }^{[16-17]}$, which is a continuously transitional structure with a thick layer of finger-like pores inside and a thin layer of small pores outsides. This asymmetric structure could provide a fast and convenient channel for gas transporting. The performance of single cells could also be benefited for this asymmetric structure.

As we known, Microstructure of the anode has significant influence on the performance of single cell. The performance of the single cell can be improved significantly by optimizing the microstructure of the anode. Anode supports with specific microstructures can be fabricated by controlling processing parameter of phase inversion technology. However, since the diversity and complication of the phase inversion, the mechanism of the structure formation is far from fully understood. Jin Chao ${ }^{[18]}$ investigated the effect of non-solvent such as water, ethanol and isopropanol etc. on the microstructure of the anode. Different microstructure of anode supports has been obtained in their research along with variation of the non-solvent. 
Moreover, organic additives in the polymer solution, as an important factor that could influence the anode structure, is the key question and one of research hot spots in phase inversion system $^{[19-20]}$. Till now, the effect of organic additives on the anode microstructure has not been clarified. In this paper, the cone shaped SOFC anode supports were successfully fabricated by phase inversion method. For demonstration the mechanism of phase inversion processes, several kinds of organic additives such as NMP, PEG-1000, acetone and oleic acid were added in the polymer solution (solvent), respectively. The effect of organic additives in the polymer solution on the microstructure of anode supports was tried to investigate in our work. The performance of single cells was also discussed subsequently. Then, the so-called segmented-in-series SOFC was assembled by two single cone-shaped cells, electrochemical property and impedance of the cell stack were investigated in details.

\section{Experimental}

Preparation and characterization of cone-shaped anode supports:YSZ (TZ-8Y, Tosoh Co., Japan) and $\mathrm{NiO}$ (Inco Co., Canada) anode powders with a weight ratio of 50:50 were mixed with graphite $(10 \mathrm{wt} . \%)$ as pore former and ethanol as medium by ball milling for $4 \mathrm{~h}$. Then the mixture was dried. Polyethersulfone (PESf), as the polymer (33 wt.\%), was dissolved in $\mathrm{N}$-methyl-2-pyrrolidone (NMP) , as solvent, with the same mass ratio to form a polymer solution. The NiO-YSZ anode powder was then mixed with the solution to obtain a viscous anode slurry. A cone-shaped mould was then immersed into the slurry to prepare the anode substrates. The diameter of the mould's open end is $35 \mathrm{~mm}$ and that of the closed end is $20 \mathrm{~mm}$. Layers of NiO-YSZ slurry were formed on the mould wall, using dip-coating technique ${ }^{[21]}$. The mould with layers of the slurry was immersed in pure water for $12 \mathrm{~h}$, which acted as a coagulant (non-solvent), to solidify the slurry. The phase inversion processes were shown in Fig.1.

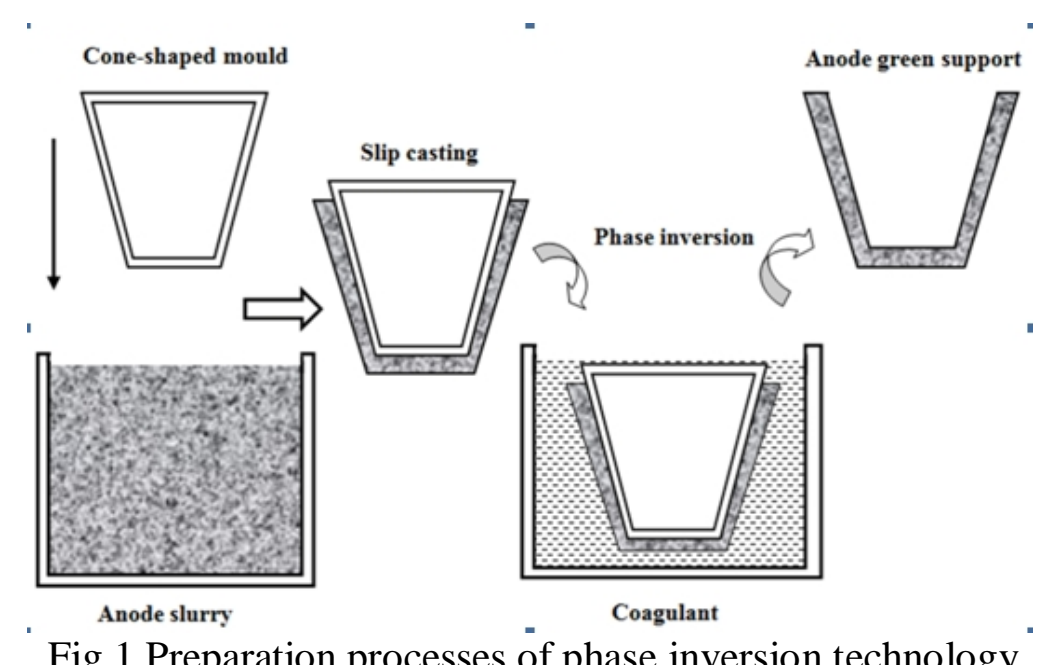

Furthermore, for demonstration the effect of different organic additives on the anode microstructure, several kinds of organic additives such as NMP, PEG-1000, acetone and oleic acid were added into the polymer solution with different weight, respectively. The detailed polymer solution composition of the slurry and additives is listed in table1 (Sample A-H). The corresponding anode substrates were prepared by the same procedures.

After that, the green substrates were removed from the mould and dried in an oven at $120^{\circ} \mathrm{C}$. The green anode substrates were then heated with a temperature raising rate of $1^{\circ} \mathrm{C} / \mathrm{min}$ and maintained at $400^{\circ} \mathrm{C}$ for $2 \mathrm{~h}$ to remove the organic binder and additives, then pre-sintered at $1200^{\circ} \mathrm{C}$ for $2 \mathrm{~h}\left(2^{\circ} \mathrm{C} / \mathrm{min}\right)$. The green anode substrates and the anode after sintered were shown in Fig. 2 . Moreover, the anode microstructure after sintered possessed a typical asymmetric structure with the surface contacting water, while the other side isolated from water was a sponge-like structure. These results were already illustrated in our previous works ${ }^{[22]}$. 
Tab. 1 Composition of the slurry with organic additives

\begin{tabular}{lcccccc}
\hline Sample & NiO+YSZ & Graphite & NMP+PESf & NMP & PEG-1000 & oleic acid \\
\cline { 2 - 7 } & \multicolumn{7}{c}{ (Mass/g) } \\
\hline A & 30 & 3 & 40 & 0 & $/$ & $/$ \\
B & 30 & 3 & 40 & 10 & $/$ & $/$ \\
C & 30 & 3 & 40 & 15 & $/$ & $/$ \\
D & 30 & 3 & 40 & 20 & $/$ & $/$ \\
E & 30 & 3 & 40 & 10 & 10 & $/$ \\
F & 30 & 3 & 40 & 10 & 15 & $/$ \\
G & 30 & 3 & 40 & 10 & 20 & $/$ \\
H & 30 & 3 & 40 & 10 & $/$ & 10 \\
\hline
\end{tabular}

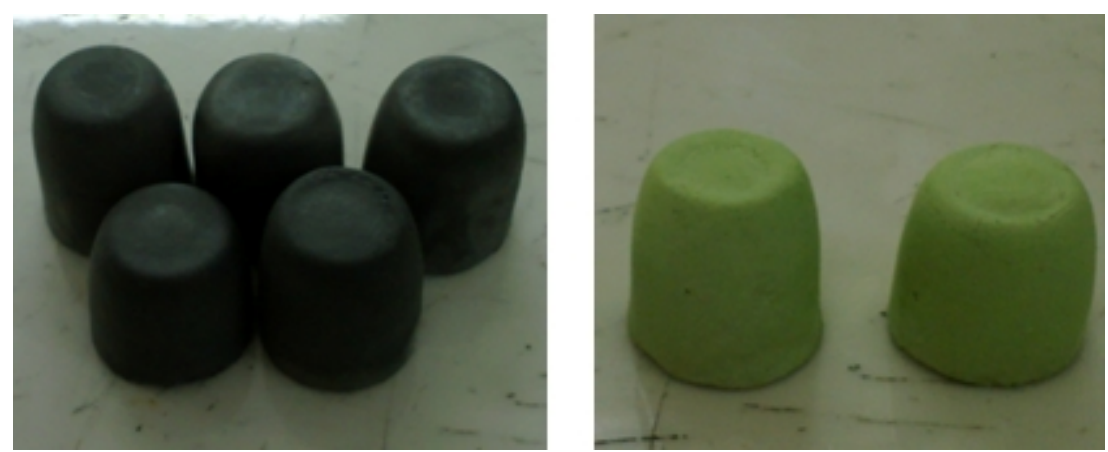

Fig.2 Green supports and supports after sintered at $1200^{\circ} \mathrm{C}$

Preparation and characterization of the single cells and cell-stack: YSZ electrolyte layers were coated on the outer surface of the anode supports with dip-coating technique ${ }^{[23]}$. Then the bilayers were fired at $1400^{\circ} \mathrm{C}$ for $4 \mathrm{~h}$ to form dense electrolyte films. $\mathrm{La}_{0.8} \mathrm{Sr}_{0.2} \mathrm{MnO}_{3}$ (LSM) cathode

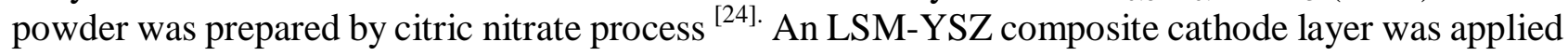
on the YSZ film of each bi-layer using a brush painting method and then a pure LSM layer was painted on the cathode for current collection. The sets with cathode were fired at $1200^{\circ} \mathrm{C}$ for $2 \mathrm{~h}$. The cathode area of each cell is $3.8 \mathrm{~cm}^{2}$. Each of the cells was attached to a ceramic tube using silver paste as sealing and joint materials ${ }^{[25] .}$ The single cell performance was tested in a temperature range of $600-800^{\circ} \mathrm{C}$, with an interval of $100^{\circ} \mathrm{C}$, using humidified $\mathrm{H}_{2}\left(3 \% \mathrm{H}_{2} \mathrm{O}\right)$ as fuel and ambient air as oxidant. Subsequently, The so-called segmented-in-series SOFC was assembled by two single cone-shaped cell. The performance of two-cell-stack was measured by the same procedures. After the electrochemical test, the cells were fractured and examined using a scanning electron microscope (SEM).

\section{Results and discussion}

Effects of organic additives on the microstructure of anode: Fig. 3 shows the microstructure of the NiO-YSZ anode sintering at $1200^{\circ} \mathrm{C}$ with $0,10,15$ and $20 \mathrm{~g}$ NMP as additives, respectively. Fig.3 (a) shows the anode microstructure with 0g NMP as additives. We can see form the Fig.3 (a) that the anode supports with so-called sandwich structure have been obtained. However, the finger-like pores is not symmetry. Some big pores are appeared below the finger-like pores. This could mainly due to viscosity of the anode slurry is too high. The phase inversion processes could be impeded by the high viscosity. Fig.3 (b) shows the anode structure with 10g NMP as additive. With the addition of NMP, the finger-like pores are extended and the big pores are reduced dramatically. The anode structure became more homogeneous. We can see from the Fig.3 (c) the anode structure become asymmetrical again along with the addition of $15 \mathrm{~g}$ NMP. Fig.3 (d) shows the anode with $20 \mathrm{~g}$ NMP. The finger-like pore decreased further and big pores are increase obviously. The variation of the anode structure in Fig.3 (c) and (d) could be caused by viscosity decreases of the anode slurry. Combination of the above results which are shown in Fig.3, anode structure with 10g NMP as 
additive might be most appropriate for SOFC. Hence, the viscosity of the anode slurry must be maintained in a certain range by phase inversion technology. High or Low viscosity could both interrupt the formation of sandwich structure.
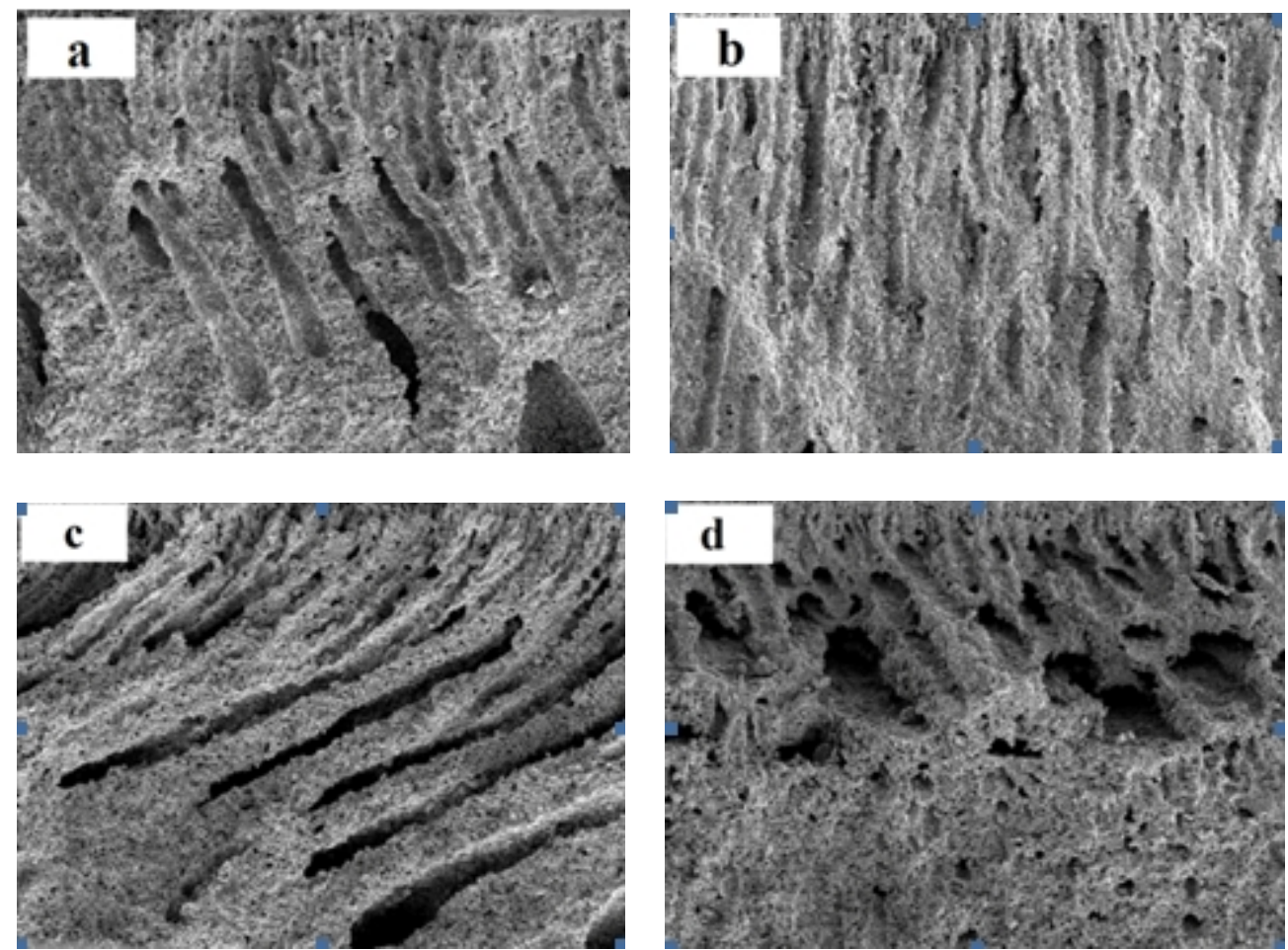

Fig.3 SEM photos of anode with NMP as additives（a Sample A, b Sample B, c Sample C, d Sample D)
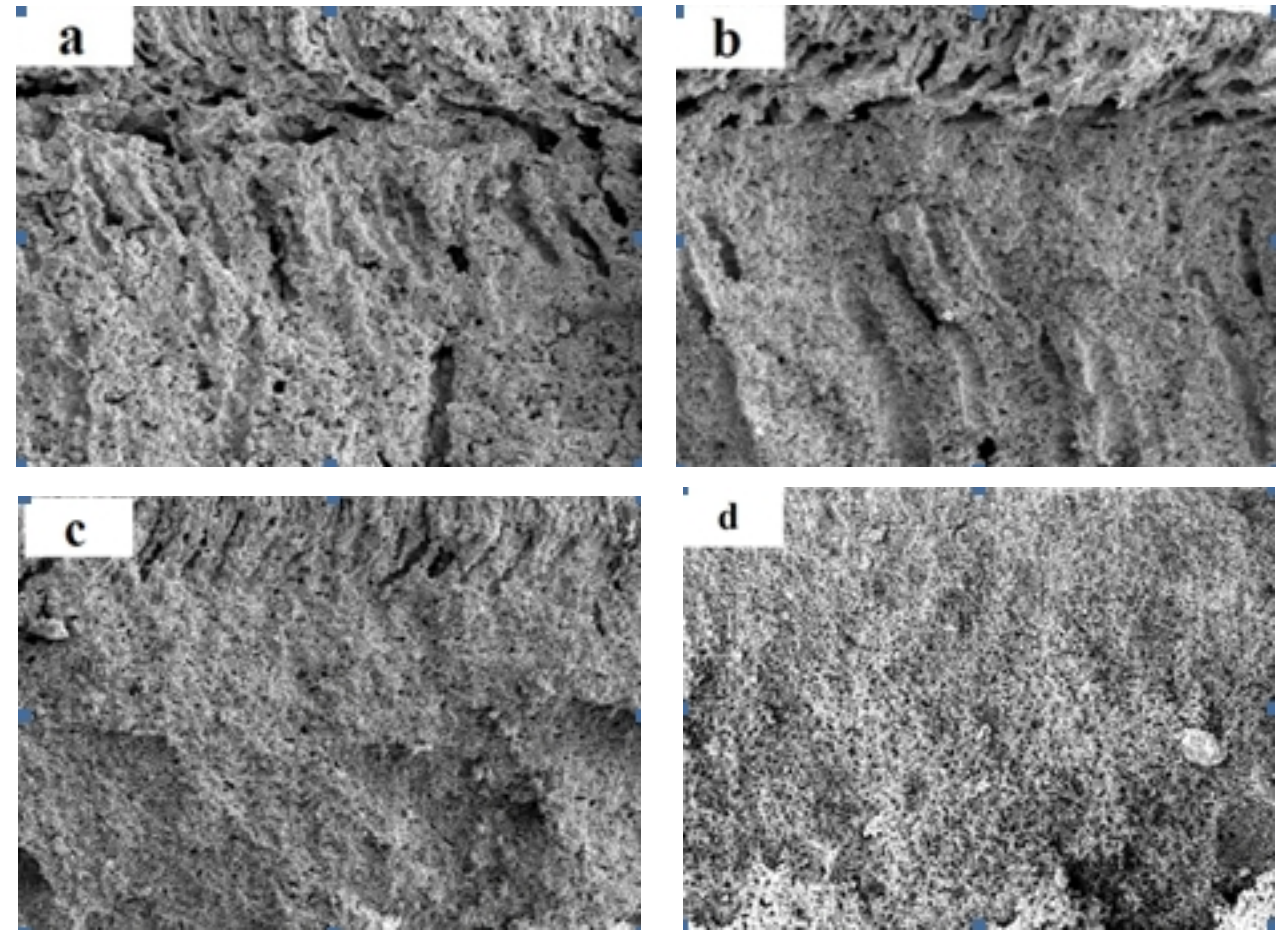

Fig.4 Photos of anode with PEG-1000 and $\mathrm{C}_{18} \mathrm{H}_{34} \mathrm{O}_{2}$ as additives (a Sample E, b Sample F, c Sample G, d Sample H)

In order to further describe the effect of different organic additives on the anode structure by phase inversion method, PEG-1000 and oleic acid were also added in the anode solution as organic 
additives. The details are shown in Tab1. Fig.4 is SEM pictures of anode after sintered with 10, 15 and 20g PEG-1000 as additive, respectively. We can see from Fig.4 that anode structure changed along with the increase amount of PEG-1000. Fig.4 (a) is the anode structure with 10g PEG-1000. As is shown in Fig.4 (a), the anode structure has changed a lot compare to the anode without PEG-1000. The small pores area enhanced and the finger-like pore decreased after 10g PEG-1000 added. As can be seen in Fig.4 (b) and Fig.4 (c), the anode structure become more and more compact and the finger-like pores are decreased further with $15 \mathrm{~g}$ and $20 \mathrm{~g}$ PEG-1000. These results are most likely because the addition of PEG-1000 could enhance the viscosity of the NMP-PESf solution, which could also affect the microstructure of the anode. The change of anode structure could also impact the performance of the single cell, which is discussed in detail later in this paper. As is shown in the Fig.4 (d), the sandwich structure completely disappeared when using 15g oleic acid as additive. Till now, the effect of organic additives on the anode microstructure has not been completely clarified. Some further studies are still needed.

Single Cell Performance: Fig.5 shows power density for single cells at 600,700 and $800^{\circ} \mathrm{C}$ with 0,10 and 15g NMP, respectively. We can see from the Fig.5 that the cells both show the highest power density at $800^{\circ} \mathrm{C}$. As is shown in the Fig.5, it is clear that the single cell with $10 \mathrm{~g}$ NMP has a higher performance, which is $195 \mathrm{~mW} / \mathrm{cm}^{2}$ at $800^{\circ} \mathrm{C}$. The reason may be that $10 \mathrm{~g}$ NMP could improve the microstructure of the anode as is shown in the SEM pictures. Optimization of anode structure could benefit the performance of the single cell. Correspondingly, the performance of single cell with 0 and 15g NMP are both decreased (Fig.5 (a) and (c)). The finger-like pores is decreased further with $20 \mathrm{~g}$ NMP as well as the single cell performance, which is not shown in this paper. Hence, 10g NMP could be optimal for the performance of single cell.
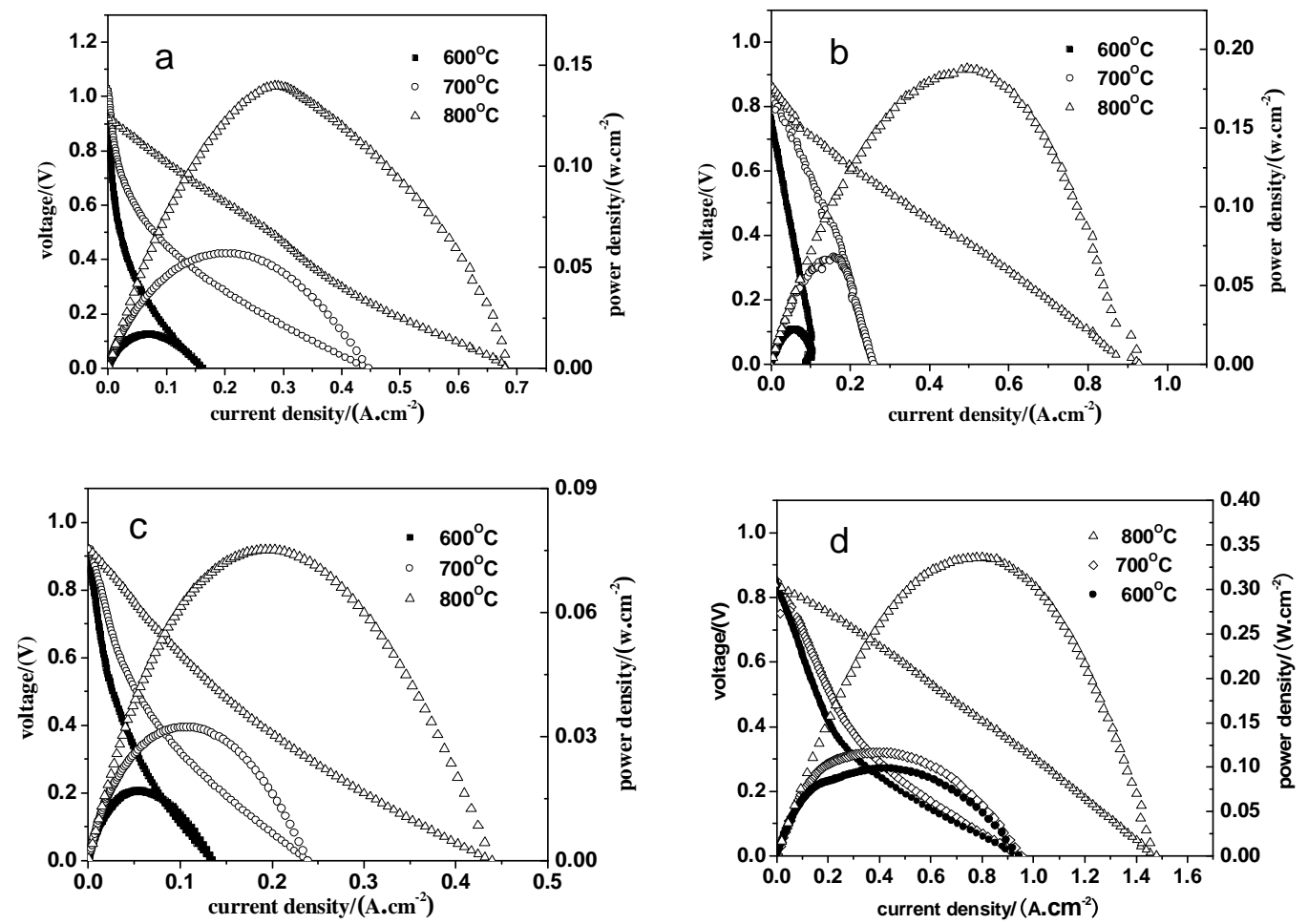

Fig.5 Performance of the single cells with different anode supports (a Sample A, b Sample B, c Sample C, d

Sample E)

Fig.5 (d) shows the power density of single cells with 10g PEG-1000 as additive. As can be seen in Fig.5 (d), addition of PEG-1000 could enhance the power density of the single cell, which is $350 \mathrm{~mW} / \mathrm{cm}^{2}$ at $800^{\circ} \mathrm{C}$. The output power is $1.33 \mathrm{w}$ of the single cell. These results are consistent with the SEM pictures of the anode structures. The performance of single cells with 15 and 
20g PEG-1000 has not been tested yet, performance of single cell with oleic acid as additive is also needed further testing.

Two Cells Stack Performance : Fig.6 shows the performance of the two-cell-stack at different temperatures. Each single cell was prepared by phase inversion technology using $10 \mathrm{~g}$ PEG as additives. The open circuit voltage (OCV) of the cell stack is $1.8 \mathrm{~V}$ at $800^{\circ} \mathrm{C}$. The maximum output power density is $250 \mathrm{~mW} / \mathrm{cm}^{2}$ at $800^{\circ} \mathrm{C}$. It can be seen that the average output power of each single cell in the two-cell-stack is $0.95 \mathrm{w}$, which is less than the single cell that is shown in Fig.5 (d). This can be explained for the preparing technique of single cell is not so stable and electrochemical performance of each cells composing the stack are not identical. It also can be seen from the Fig. 6 that high concentration polarization is exit when the cell is operated at higher temperature.

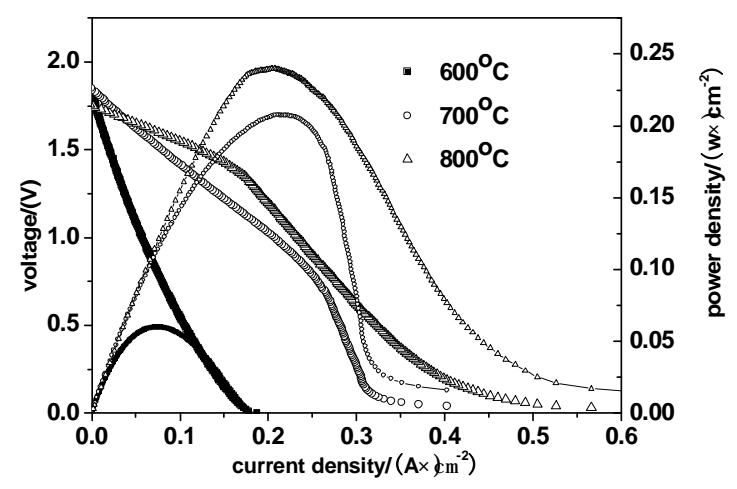

Fig.6 Powder density of the two-cell-stack

\section{Conclusion}

Cone-shaped tubular NiO-YSZ anode supports were fabricated by phase inversion technology. NMP was added in polymer solution as additive for improving the anode structure. The SEM results show that the anode with 10g NMP as additive has a better structure, the finger-like pores and the small pores of the anode is appropriate. The difference of anode structures with different amount of NMP could be attributed to the viscosity changes of the polymer solution. The single cell with $10 \mathrm{~g}$ NMP provides a higher electrochemical property, which is $195 \mathrm{~mW} / \mathrm{cm}^{2}$ at $800^{\circ} \mathrm{C}$. In addition, PEG-1000 was then added in the polymer solution when 10g NMP as additive. The anode structure was further optimized with addition of PEG-1000. The maximum power density of single cell is $350 \mathrm{mw} / \mathrm{cm}^{2}$ at $800^{\circ} \mathrm{C}$ with $10 \mathrm{~g}$ PEG-1000. The SEM picture shows that the finger-like pores disappear when using oleic acid as additive. Moreover, two cells stack were successful prepared and tested. The cells stack provides maximum power density of $250 \mathrm{~mW} / \mathrm{cm}^{2}$ at $800^{\circ} \mathrm{C}$.

\section{Acknowledgements}

This work was financially supported by the Guangdong Natural Science Foundation (2015A030310468) and Scientific Research Foundation of Southern Medical University.

\section{References}

[1] Wang W, Ran R, Shao ZP. Combustion-synthesized $\mathrm{Ru}-\mathrm{Al}_{2} \mathrm{O}_{3}$ composites as anode catalyst layer of a solid oxide fuel cell operating on methane. Int. J Hydrogen Energy, 36(2010): 755-64.

[2] Park EW, Moon H, Park MS, Hyun SH. Fabrication and characterization of Cu-Ni-YSZ SOFC anodes for direct use of methane via $\mathrm{Cu}$-electroplating. Int. J Hydrogen Energy, 34 (2009):5537-5345. 
[3] Pusz J, Smirnova A, Mohammadi A, Sammes NM. Fracture strength of micro-tubular solid oxide fuel cell anode in redox cycling experiments. J Power Sources, 163(2007):900-906.

[4] Suzuki T, Yamaguchi T, Fujishiro Y, Awano M. Fabrication and characterization of micro tubular SOFCs for operation in the intermediate temperature, J Power Sources, 160(2006): 73-77.

[5] Sammes NM, Du Y, Bove R. Design and fabrication of a 100W anode supported micro-tubular SOFC stack. J Power Sources, 145(2005): 428-434.

[6] Cheekatamarla PK, Finnerty CM, Cai J. Internal reforming of hydrocarbon fuels in tubular solid oxide fuel cells. Int J. Hydrogen Energy, 33(2008):1853-1858.

[7] Sui J, liu J. Slip-cast $\mathrm{Ce}_{0.8} \mathrm{Sm}_{0.2} \mathrm{O}_{1.9}$ cone-shaped SOFC. J Am Ceram Soc, 91(2008): 1335-1337.

[8] Zhang YH, Liu J. Fabrication and performance of cone-shaped segmented- in-series solid oxide fuel cells. Int. J Appl Ceram Technol, 5(2008): 568-73.

[9] Yan Liu, Yubao Tang, Jiao Ding, Jiang Liu, Electrochemical performance of cone-shaped anode-supported segmented-in-series SOFCs fabricated by gel-casting technique,Int J. Hydrogen Energy, 37(2012): 921-925

[10] Peter Blennow, Kent K. Hansen, L. Reine Wallenberg, Mogens Mogensen, Effects of Sr/Ti-ratio in SrTiO3-based SOFC anodes investigated by the use of cone-shaped electrodes, Electrochimica Acta, 52(2006): 1651-1661

[11] Yaohui Bai, Jiang Liu, Hongbo Gao, Chao Jin, Dip coating technique in fabrication of cone-shaped anode-supported solid oxide fuel cells, Journal of Alloys and Compounds, 48(2009): $554-557$

[12] Cong Ren, Tong Liu, Yating Mao, Panita Maturavongsadit, Jittima Amie Luckanagul, Qian Wang, Fanglin Chen, Effect of casting slurry composition on anode support microstructure and cell performance of MT-SOFCs by phase inversionmethod, Electrochimica Acta, 149(2014): 159-166

[13] Hua Huang, Jie Lin, Yunlong Wang, Shaorong Wang, Changrong Xia, Chusheng Chen, Facile one-step forming of $\mathrm{NiO}$ and yttrium-stabilized zirconia composite anodes with straight open pores for planar solid oxide fuel cell using phase-inversion tape casting method, Journal of Power Sources, 274(2015): 1114-1117

[14] Changcheng Chen, Mingfei Liu, Lei Yang, Meilin Liu, Anode-supported micro-tubular SOFCs fabricated by a phase-inversion and dip-coating process, International Journal of Hydrogen Energy, 36(2011): 5604-5610

[15] Li Bai, Lan Zhang, Hong Quan He, Raj Kamal S/O Abdul Rasheed, Cai Zhi Zhang, Ovi Lian Ding, Siew Hwa Chan, Journal of Power Sources, 246(2014): 522-530

[16] Ismail AF, Yean LP, App J. Review on the development of defect-free and ultrathin-skinned asymmetric membranes for gas separation through manipulation of phase inversion and rheological factors. J Appl Polym Sci, 88(2003): 442-451.

[17] Itta AK, Tseng HH. Effect of dry/wet phase inversion method on fabricating polyetherimide-derived CMS membrane forH $\mathrm{H}_{2} / \mathrm{N}_{2}$ separation. Int. Journal Hydrogen Energy, 35(2010):1650-1658.

[18] Chao Jin, Jiang Liu, Lianhe Li, Yaohui Bai, Electrochemical properties analysis of tubular NiO-YSZ anode-supported SOFCs fabricated by the phase-inversionmethod, Journal of Membrane Science, 341(2009): 233-237 
[19] Chenghao Yang, Chao Jin, Fanglin Chen, Micro-tubular solid oxide fuel cells fabricated by phase-inversion method, Electrochemistry Communications, 12(2010): 657-660

[20] Naitao Yang, Xiaoyao Tan, Zifeng Ma, A phase inversion/sintering process to fabricate nickel/yttria-stabilized zirconia hollow fibers as the anode support for micro-tubular solid oxide fuel cells, Journal of Power Sources, 183(2008): 14-19

[21] Alireza Torabi, Thomas H. Etsell, Partha Sarkar, Dip coating fabrication process for micro-tubular SOFCs, Solid State Ionics, 192(2011): 372-375

[22] Handuo Wang, Jiang Liu, Effect of anode structure on performance of cone-shaped solid oxide fuel cells fabricated by phase inversion, International Journal of Hydrogen Energy, 37(2012): 4339-4345

[23] Bai YH, Liu J, Gao Hongbo, Jin C. Dip coating technique infabrication of cone-shaped anode-supported solid oxide fuelcells. J Alloys Compd, 480(2009): 554-557.

[24] Ding J, Liu J. A novel design and performance of cone-shaped tubular anode-supported segmented-in-series solid oxide fuel cell stack. J Power Sources, 193(2009): 769-773.

[25] Liu J, Su WH, Lv Z, Ji Y, Pei L, Liu W, et al. Chinese Patent: ZL0 1 33049. 2, 2004. 